\title{
Hotel-Related Factors and Employee Performance "The Case of Jordanian Four Star Hotels"
}

\author{
Ashraf Mohammad Alfandi ${ }^{1}$ \\ ${ }^{1}$ Department of Tourism Management, Irbid National University, Irbid, Jordan \\ Correspondence: Ashraf Mohammad Alfandi, Department of Tourism Management, Irbid National University, \\ Irbid, Jordan.
}

Received: January 2, 2020

Accepted: January 24, $2020 \quad$ Online Published: February 10, 2020

doi:10.5539/ibr.v13n3p68

URL: https://doi.org/10.5539/ibr.v13n3p68

\begin{abstract}
The study addresses the challenge of employee performance (EP) at the four-star hotels in Jordan by focusing on how hotel-related factors influencing EP. Multiple regression was used to predict EP and explain the impact of five predictors that are organization culture (OC), organization structure (OS), manager attitude (MA), empowerment (EM), and training culture (TC). A correlation was used to compare the relationship between study variables. The results of multiple regression indicated that EM was the strongest predictor of EP followed by MA, and TC, whereas OS and OC found to not influence the EP. Overall interrelations among the independent variables showed a positive strong relationship and positively related to EP. Based on the study findings, several recommendations are offered. Finally, the implications for management are discussed.
\end{abstract}

Keywords: Employee Performance (EP), Empowerment (EM), Organization Culture (OC), Organization Structure (OS), Manager Attitude (MA), Training Culture (TC), Hotels, Jordan

\section{Introduction}

Factors such as the constantly changing market environment, globalization, and diverse workforce, made the human resources at any organization a key element to achieve its objectives and ensure its success (Elnaga \& Imran, 2013). Human resources are the most significant assets as their performance defines service quality and delivery. Therefore, a well-defined evaluation of employee performance (EP) determines the success or failure of any organization as well as the smooth running of the working process. The significance of measuring EP comes from the fact that if you are aware of your EP and capabilities, and what factors influence them positively or negatively, you will be able to manage them effectively (Boxall \& Purcell, 2011). Hence, it is generally agreed that the more manager can answer the question of what influence their EP, the more effective they will be at enhancing their organization general performance (Alfandi, 2016a). Cooke, (2000) defined EP as the accomplishment of specified tasks measured against predetermined standards of accuracy, completeness, cost, and speed. The literature identified there major related factors that could influence EP at any organization; these are firm-related factors, employee-related factors, and job-related factors. According to Armstrong, (2000) the firm-related factors are the firm's internal and external environment such as management support, training culture (TC), organizational climate and environmental dynamism. On the other hand, job-related factors are those factors associated with the job such as communication, autonomy and the job environment. Employeerelated factors are those factors that only related to the employees such as their turnover intention, absenteeism, skill flexibility, commitment, skill level, proactivity, and adaptability (Mathis \& Jackson 2011; Armstrong 2000).

Even though many related factors have been examined in the literature regarding their impact on EP, the purpose of current research is only to explore the firm-related factors that could have an influence on the EP at the four-star hotels in Jordan. Besides, although the separate impact of several factors on the EP is established in the literature, the contribution of this research is the combination of firm-related factors -which we referee to it in the present study as the hotel-related factors- in addition to the correlations between them and EP.

Therefore, the present study searches for answering the following key research questions:

RQ. 1: What are the hotel-related factors that influence EP at the four star hotels' sector in Jordan?

RQ. 2: Which hotel-related factor has the greatest influence on the EP?

RQ. 3: What are the correlations between the hotel-related factors and the EP? 


\section{Problem of the Study}

Guests at the Jordanians' hotels may experience numerous challenges during their stay such as the language barriers, traveler's expectations and inaccurate/accurate information concerning the host culture. Besides, from the point of view of international tourists, the region where Jordan is located seen as a risky and unstable region in terms of safety and security (Khasawneh \& Alfandi, 2019). The literature review showed that the development of any organization is directly dependent upon the performance of the human element through work quantity, quality, as well as the speed of work achievement, which reflects on the overall performance in the organization (Alfandi, 2016a). As such, it is essential to the success of the hotel industry in Jordan to provide a high level of service quality that could be ensured by a high level of its EP.

According to Assaf \& Jossiassen (2016), while most of the previous studies in the literature focused on comparing the international hotels' performance, only a few studies conducted to investigate the factors that influencing the hotel's EP. This holds true in the context of the Jordanian hotel sector. In addition, there is a lack of previous studies that combined the firm-related factors together to investigate the correlations between them as well as their influences on EP at the four-star hotels, particularly in Jordan. Hence, the present study tends to overcome this issue and provides insight and recommendations for the Jordanian hotels by the factors that are related to their hotels that influencing their EP.

\section{Literature Review and Hypothesis Development}

\subsection{EP in Hotel Industry}

In general, the concept of performance related to the outcomes and accomplishments achieved by organization, group or a single person (Rothwell et al., 2007). The performance of an organization is the ability to compete in the market, the achievement of goals and meet customer's needs. On the other hand, individual performance refers to the people that are performing activities associated with work that is related to the organization's goals (Heck \& Marcoulides, 1993). EP is not only a matter of what employee achieves but also how they achieve it. EP in the hotel industry become more significant than any other industry as the hotel industry depends generally on their employees and it is a labor-intensive industry that relies heavily on human interaction or activities. That is because in the hotel industry the employees are having direct contact with the customers, and if they perform well, the customers will be pleased and satisfied. Managing EP in the hotel and tourism industry compared to other industries represents the most critical point of hotel management. Therefore, EP affects the productivity of the hotel, profits, market position, and sales, therefore, the success or failure of a hotel depends largely on the quality of services provided by the employees of the hotels.

EP could be seen and measured in different ways, for instance, Edgar \& Geare (2005) consider four main elements to manage EP; these are the work to be performed, where to perform it, how to perform it, and the expected results of this performance. Others see EP as the amount of the physical or mental energy that the individual spends in a specific period in the work. While some focus on the quality and the number of given efforts, others refer to it as how the work duties are done. EP could be also measured by looking at the rates of performance, which is the process in which the evaluator increases the employee's productivity to determine the efficiency, the quality and the amount of the employee's work in a specific period (Uddin, Luva, \& Hossain, 2013). In the current study, EP will be measured through the dimensions of the quantity of work, quality of work, speed of work achievement as was suggested by the previous work of Mathis \& Jackson (2009).

\subsection{Organization Structure}

Organizational structure (OS) refers to the arrangement of a task, interrelations of various departments and levels of authorities to achieve co-operation of efforts, a delegation of authority and effective communication along the scalar chain of command (Liao et al., 2011). It was identified as a system used to define a hierarchy within an organization, which identifies each job, its function and where it reports to within the organization ((Tran \& Tian, 2013). Researchers have sought to determine which OS brings the most advantages and they have suggested that OS should be responsive to positive or negative consequences for both organizations and individuals' performance (Conner \& Douglas, 2005).

OS is one of the most important factors that could influence EP in the hotel industry in either a positive or negative manner. In addition, the literature suggested that OS have considerable correlations with TC, leadership styles, organizational performance, innovation, employees' trust and job satisfaction, job involvement, and EP (Garg \& Krishnan, 2003; Jiang, 2011; Ağar et al., 2012; Mehrabi et al., 2013). An OS that ensures a positive impact on the performance of the employee is the one that relies on management control, economic principles, cash flow, and efficiency. However, due to the several problems connected with employees that hotel industry 
facing, such as the lack of trained employee, high turnover intention, and reasonability, most of the hoteliers turn to the easiest solution by cutting costs intended to the payrolls, bonuses, or training and educations (Bakker \& Schaufeli, 2008). As such, it is essential to investigate the role that OS plays in influencing EP in the Jordanian hotel sector.

\subsection{Training Culture}

The literature review confirms several factors that could influence individual mechanisms. However, Elnaga \& Imran, (2013) believe that those employees who receive effective training sessions are more able to perform well on their jobs. They demonstrate that training increase the quality of work and service delivery, which leads to achieving organizational goals and gaining competitive advantage. Alfandi, (2016b) investigated the training impact on the performance of employees in Jordanian travel and tourism institutions. The study confirmed that training had great impacts on the EP. Besides, tourism institutions in Jordan provide an adequate level of training to employees; however, it is not continuous. Another study by Badado, (2006) revealed that the unavailability of the scientific competences to perform training in the Jordanian tourism sector negatively affects EP. In the same line, Seamen \& Eves, (2005) confirm the positive influence of training when delivered to hotel employees. They demonstrate that training has great and positive effects on employee behavior in general. Another study in the field of hospitality industry conducted by Griffin \& Neal, (2000) indicated that training to perform safely in the workplace impacts individual safety. Finally, Garavan, (1997) provides evidence of the positive impact that social skills training can have on improving the quality of customer service within a hotel environment.

It is important to note that we discuss the culture of training inside the four-star hotels and not the influence of given training on EP. TC defined as the aggregate of meaning, values, practices, attitude, and behavior to invest in training and development so that organizational knowledge and skills could be enhanced (Gautam, 2018). It is a set of meanings and values attributed to training in a specific organization (Polo, Cervai \& Kantola, 2018). It is the policies and formal learning environment that motivates all the people associated in the organization to create, share and transfer knowledge and experiences.

Hofstede (1998) agreed that TC is an attribute of an organization established and measured toward individuals combined to the level of the organizational unit. As such, TC could be the only way to reduce the cost of hiring competent employees and reducing the cost of losing a competent employee. The fact is that most organizations are not realizing the importance of TC in their organizations to increase productivity. They believe that training could be costly to give, however, it saves time and costs in the long run and it gives back that it took (Kaynak, 2003; Baum \& Devine, 2007). It is organization investments that bring return on investment and supports the achievement of competitive advantage (Elnaga \& Imran, 2013), by providing employees with the required technical skills to carry out their work efficiently and effectively (Jabeen, 2011), that should positively affect their performance at the workplace (Horng \& Lin, 2013; Gana \& Bababe, 2011).

\subsection{Organization Culture}

Organizational culture (OC) is a set of shared values, beliefs and norms that influence the way employees think, feel and act in the workplace (Schein, 2011). Early studies agreed that the level of well-managed, strong, and supportive OC is related to the level of performance of an organization through positive EP (Egan, Yang \& Bartlett, 2004; Heck \& Marcoulides, 1993). Researchers claimed that OC is inherently connected to organizational practices and supporting values that create a positive impact on employees' attitudes and behaviors, which in turn positively influence their performance (Hellriegel \& Slocum, 2009; Ferris et al., 1998). In the context of the hotel sector in Jordan, a study by Alsheikh, et al., (2018) found that leadership style, organizational commitment, quality management practices (QMPs) and OC significantly affect various hotel processes as well as employees' performance. In the Swiss hotel industry, Tajeddini (2011) found that OC, besides other variables, positively influencing organization and EP and assisted in achieving long-term profitability. More recent studies recommended the examination of OS direct relationship with performance (e.g., Elnihewi, 2015; Wunderlich \& Beck, 2017).

A supportive OC motivate, shape and channeling the employee behaviors towards the fulfillment of corporate goals. On the other hand, a weak OC forcing employees to attain their goals (Daft, 2010), that is because OC failed to fulfill the internal integration and coordination between the organization and its employees (Furnham \& Gunter, 1993).

\subsection{Manager Attitude}

Manager attitude (MA) is the manager's ability to influence subordinates to perform at their highest capability, which could be positive or negative (Mathis \& Jackson, 2009). A positive MA influences the satisfaction of 
employees (McNeese-Smith, 1997) and if the employees are stratified about their manger attitude, their job productivity will increase (Alfandi, 2016a). In this regard, the theory of Leader-Member interaction developed to explain the two-way relationship between the manager and the employee. The theory suggests that a manager does not correspondingly treat all subordinates and focuses on mutual relations that every leader establishes (Cole, 2002). Normally, managers have limited time and resources to interaction with the audience similarly (Zhang, Leng, \& Xu, 2019), hence, a high level of trust, respect, and compliance with obligations are the main determinants of the changing relationship and the reason to increase their performance (McNeese-Smith, 1997; Seamen \& Eves, 2005). The influence of positive or negative MA on their performances has been confirmed in the literature Seamen \& Eves, 2005; Khan et al., 2014; Alfandi, 2020; Truckenbrodt, 2000; Pellegrini \& Scandura, 2006; Liden \& John, 1998; Scandura \& Schriesheim, 1994; Liden \& Graen, 1980; Klein \& Kim, 1998).

\subsection{Empowerment}

Generally, empowerment (EM) means to give power or to give authority. In the context of business management, EM is assigning decision making power to employees and making them responsible for the results (Kenneth, Wheeler, \& Kacmar, 2009). Hence, EM is a managerial concept that gives employees sufficient freedom to make decisions in order to make them more motivated and committed to the organization (Somayyeh \& Morteza, 2015). Choong, Wong \& Lau, (2011) agreed that EM is a motivational technique for building trust in organizations between managers and employees. Diverse scientific literature and practical examples demonstrate the importance of EM and its causal connection to EP by making stronger task commitment, higher levels of initiative in carrying out role responsibilities, positive values, more innovation and learning, higher job satisfaction and strengthened the OC (Thomas \& Velthouse, 1990). EM leads to the high performance of employees as they feel they are valued by their organization, thus, employees with EM will perform better than those working in centralized OS (Choong, Wong \& Lau, 2011).

Therefore, based on the above reviews and arguments, the following research hypotheses are proposed:

H1: OS affects employee's performance positively.

H2: TC affects employee's performance positively.

H3: OC affects employee's performance positively.

H4: MA affects employee's performance positively.

H5: EM affects employee's performance positively.

\section{Methodology}

Using a quantitative methodology, the current study intended to examine the impact of selected hotel-related factors on the EP at the four-star hotels in Jordan. The study used a convenient sampling method to distribute a close-ended, structured self-administered survey as a data collection technique. A set of five points Likert scales were used to measure pertinent constructs where (1) strongly disagrees and (5) strongly agrees). Initially, the developed scale of the present study contained 35 items. However, the scale went through the process of validity and reliability. First, the questionnaire measures have been adapted to Arabic by following the method of forward-backward translation from the lecturers. Also, all measures have been modified to fit the context of the study based on recommendations from tourism experts at Irbid National University (INU). Then, a pilot test was conducted on 21 students at the same university to assess how well each scale captured the construct that it was supposed to measure. Based on the Gronbach Alpha, the score ranged between $64 \%$ and $81 \%$ for 32 items of the questionnaire, which consider suitable according to the acceptable percentage presented by (Hair, Money, Samouel, \& Page 2007) this is $60 \%$. The other 3 items were removed from the analysis as their factor loading under the 0.60 .

EP was conceptualized as the quantity of work, quality of work, and speed of work achievement. Thus, it was measured using nine (9) items adopted from Alfandi, (2020). Five variables consisting of (23) items have been employed to measure the hotel-related factors affecting the EP. More specifically, to measure TC, four items were adopted and modified from previous work of (Galanou \& Priporas, 2009; and Polo, Cervai, \& Kantola, 2018). For MA, four items were adopted from Kalkavan \& Katrinli, (2014) who previously adopted it from Hackman \& Oldman, (1975). The OC instruments that were used in this study are six items adopted from previous work by Al-Yahya, (2008) who previously adopted it from Glaser et al., (1987). Glaser et al., (1987) provided four operational measures of OC grounded in both management and communication research: teamwork, climate-morale, involvement, and management supervision. Five items were adopted from Garg \& Krishnan, (2003) to measure the OS. Finally, from a study by Somayyeh \& Morteza, (2015), four items were 
adopted to measure employee EM.

A descriptive-analytical approach of data analysis was applied through a field survey of the statistics community and then analyzing the collected data by (SPSS version 20) for testing the hypotheses through regression analysis. The various influencing hotel-related factors (OC, OS, MA, TC, and EM) were regressed as independent variables against the dependent variable of EP.

In terms of the study population, according to the Jordanian Ministry of Tourism and Antiquities (2019), there are 33 four-star hotels in Jordan, 24 of them located in the capital Amman. The number of employees working in hotels in Jordan reached 20500 employees. Approximately 12600 employees working in classified hotels (from one to five stars) located in Amman. Of the 12600 employees, around 2000 employees working in the four-star hotels that are located in Amman the capital of Jordan. As such, the study population that consists of employees working in the four-star hotels in Amman is around 2000 employees. In terms of sample size, Roscoe (1975) has mentioned that the most appropriate sample size of most researches is larger than 30 and smaller than 500. In the context of the tourism industry, Veal (2006) mentioned that the sample size of 10,000 populations equals 370 sample units. Based on this, and to choose a safe number of respondents, the sample size that was considered in this study is 160 respondents as we have about 2000 employees as the study population. The population of the study consists of employees working in four-star hotels located in Amman the capital of Jordan (24 four-star hotels found in Amman). The sample was chosen through a convenient sampling method and it consisted of full-time employees working in deferent departments in selected four-star hotels located in Amman. As for the respondents of the sample, they were 160 employees who received questionnaires. 146 questionnaires were returned, which forms $91 \%$ of the sample. Of these, 6 were found to be invalid, resulting in 140 valid surveys that finalized a response rate of $87 \%$.

\section{Data Analysis}

\subsection{Characteristics of the Study Sample}

The population of the current study consists of employees at four-star hotels in Jordan. After data collection, more than $65 \%$ of the sample was males. About $80 \%$ of the study sample was those who have a Bachelor's degree and diploma. Around $63 \%$ of the sample has less than 5 years of experience in the hotels' sector, and only $6 \%$ having more than 15 years of experience in the hotels' sector. In terms of position title, more than $64 \%$ of the sample was the executive's workers.

\subsection{Descriptive Statistical Test of the Study Variables}

The general arithmetic means of the sample perceptions towards their job performance at the Jordanian four-star hotels reached (3.7) which show a good percentage of employees' job performance. They believe that they create effective work relationships with others and they adapt easily to changing situations in addition to strive to meet deadlines at work. However, they are not assuming a sense of ownership and responsibility in the quality of personal performance.

In terms of the attitudes of the sample towards TC at Jordanian four-star hotels, the arithmetic means ranges from (2.4) in their least limit for the paragraph "The hotel provides yearly systematic training plan " to (4.2) in their highest limit for the paragraph "the hotel provide credit or priority to the trained employees". The general arithmetic mean was close to the neutral level with arithmetic mean reaching (3.0). Employees at the four-star hotel in Jordan believe that the hotel does not give a systematic training plan in a yearly way and training plans and programs of the hotel are not under continuous development. Still, they granted that the benefits from training they get by accomplishing their job tasks better and faster. Regarding the perception of MA at the Jordanian four-star hotels, the general arithmetic means reached (3.3) which show a quite good percentage of employees' satisfaction. They agreed that the positive attitude of their manager could influence their performance.

The arithmetic means of the attitudes of the sample towards the EM range from (1.8.) in their least limit for the paragraph "my manager considers my ideas when he disagrees with them" to (2.4) in their highest limit for the paragraph "my manager encourages me to express my ideas and suggestions".

Finally, regarding the perceptions of the study sample toward OS, the general mean reached (3.2) which consider medium level. Employees at the Jordanian four-star hotels approved that even their hotels determine formal relations and show the number of levels in the hierarchy and they define the span of the control of managers, however, their hotel structure did not determine the position of people as working in group in a unit and it divides the units in the entire organization. 


\subsection{Correlation Analysis}

In order to answer the third research question which is (What are the correlations between the hotel-related factors and the EP?) and to obtain understanding of the relationship between the study variables, correlations, standard deviations and means have been computed, related with EP, OS, OC, EM, TC, and MA. Generally, the correlation is significant when the value is less than 0.05 . The table below illustrated the relations.

Table 1. Means, standard deviations and correlations of the study variables

\begin{tabular}{|c|c|c|c|c|c|c|c|c|}
\hline Variables & Mean & SD & 1 & 2 & 3 & 4 & 5 & 6 \\
\hline EP & & .83 & 1 & & & & & \\
\hline $\mathrm{OC}$ & 2.90 & .77 & $.642 * *$ & 1 & & & & \\
\hline $\mathrm{TC}$ & 3.04 & .85 & $.685 * *$ & $.544 * *$ & 1 & & & \\
\hline EM & & .91 & $.714 * *$ & $.423 * *$ & $.424 * *$ & 1 & & \\
\hline MA & 3.32 & .79 & $.323 * *$ & $.527 * *$ & $.643 * *$ & $.545 * *$ & 1 & \\
\hline OS & & .75 & $.225 * *$ & $.423 * *$ & $.673 * *$ & $.444 * *$ & $.478 * *$ & 1 \\
\hline
\end{tabular}

As seen in the table above, the results showed that all variables in the research model are significantly correlated. Correlation analysis results revealed that a strong correlation has been found between EM and EP $(r=0.71$, $\mathrm{p}<0.01)$ followed by strong correlations between the TC and OC with EP with the correlations of $(r=0.68$, $\mathrm{p}<0.01)$ and $(\mathrm{r}=0.64, \mathrm{p}<0.01)$ respectively. On the other hand, a moderate relationship between MA with EP has been found with the correlations of $(0.32, \mathrm{p}<0.01)$. However, a low correlation has been found between OS and EP with the correlation of $(0.22, \mathrm{p}<0.01)$.

\subsection{Hypotheses Testing}

The multiple regressions were used to test the hypotheses of the study as there is more than one independent variable (EM, OS, OC, TC, and MA) affecting the dependent variable (the EP). To interruption, the regression analysis result, the Standardized Coefficient Beta and $\mathrm{R}$ square are used. If $\mathrm{R}$ square calculated value was higher than its tabulated value that provides evidence whether to support the hypotheses stated earlier.

Table 2. The influence of (EM, OS, OC, TC, and MA) on EP

\begin{tabular}{lccccccc}
\hline $\begin{array}{l}\text { Independent } \\
\text { variable }\end{array}$ & $\mathrm{B}$ & SE B & $B$ & Sig. P<.05 & $\begin{array}{l}\text { R } \\
\text { square }\end{array}$ & F & $\begin{array}{l}\text { Sig. } \\
\text { p }<0.01\end{array}$ \\
\hline OC & .221 & .048 & .021 & .074 & .311 & 19.9 & $0.00^{* *}$ \\
\hline TC & .144 & .048 & .071 & .000 & & \\
\hline OS & .115 & .058 & .033 & .069 & & \\
\hline MA & .174 & .032 & .140 & .002 & & \\
\hline EM & .263 & .060 & .219 & .007 & & \\
\hline
\end{tabular}

B: Unstandardized coefficient beta:

SEB: standard error of regression coefficient;

$\beta$ : Beta coefficient.

From the first run of the regression analysis, the casewise diagnostics indicate that observation numbers 17 and 113 found to be outliers and hence deleted in the next regression run. As can be seen in the table above, the value of calculated $\mathrm{F}$ is higher than tabulated $\mathrm{F}$ value at the confidence level $(\alpha \leq 0.05)$, and the value of the statistical significance level is (0.000) which is less than the value of the confidence level $(\alpha \leq 0.05)$. The F-statistic $(F=$ $19.9051, \mathrm{p}<.01)$ indicates that the relationship between independent and dependent variables is significant. The $\mathrm{R}$ square obtained indicates that the independent factors account for $31 \%$ of the variation in the EP.

Regarding the first research question, which is (What are the hotel-related factors that influence EP at the four-star hotel sector in Jordan?), the result revealed that three out of five independent variables found to have a significant effect on EP. These are EM, MA, and TC. Consequently, it is fair to say the following hypotheses are accepted (H2, H4, and H5). Nonetheless, the result showed that OC and OS do not influence EP. As such, the hypotheses (H1 and $\mathrm{H} 3)$ are rejected.

The beta values were used in order to answer the second research question that is (Which hotel-related factors factor has the greatest influence on the EP?). Based on the size of beta values, the predictors' variables exercising the most influence on EP were $\operatorname{EM}(\beta=.22)$, followed by MA $(\beta=14)$ and finally TC $(\beta=.7)$. 


\section{Conclusion}

EP is thought to be one of the most significant factors influencing the success of the hotels' sector in the nowadays-competitive market. This study aimed to investigate the correlation between five hotel-related factors and EP. More specifically, the five factors that have been examined are (OC, OS, TC, EM, and MA). The findings showed that all five hotel-related factors are significantly correlated with EP, and the strongest correlations were between EM and TC with EP respectively. Further, the five investigated factors are not only correlating with EP but also affect each other indirectly. Also, this study examined the influence of the five hotel-related factors that could influence the EP at the four-star hotels in Jordan. The findings revealed that EM has the greatest influence on EP followed by MA and TC respectively. Duvall, (1999) agreed that employee and organization accomplishments are a consequence of EM. This study proved that EM affects EP as they feel they are valued by their organization. MA found to have an effect on EP at Jordanian travel and tourism institutions. Alfandi, (2020) agreed that MA helped employees to become more effective in carrying out of their duties to improve performance through the increasing level of individual competences. The same result confirmed by several previous studies that found that MA will lead to a high level of EP through, trust, confidence to their employee, and unbiased behavior toward their employees (Seamen \& Eves, 2005; Khan et al., 2014; Alfandi, 2016a). Through this study, the researcher emphasizes the strong relationship between TC and EP. Training is a non-financial motivator to reward employees to help them to perform better and participate more in their works. TC could be seen as a successful technique for superior EP to provide a high-quality service for the tourists which becomes a very important determinant for enhancing the hotel's competitive advantage in the market. The findings also showed that there was no significant influence of OC and OS on EP. This could be because the impact will occur if mediated by employee behavior as stated by (Syauta, 2012; Ghani, 2006; Rousseau, 1990).

\section{Recommendations and Limitations}

Counting upon the study results, we exhibit here the most important recommendations for the four-star hotels. The current study provides a better understanding for hotel managers regarding hotel-related factors in order to foster EP. We agreed here that some of the hotel-related factors resulting in a higher level of job performance. Four-star hotel managers should keep on giving pieces of training to their employees and pay more attention to the training program and put it into force. Training culture inside the hotels found to have several advantages as they found to improve the employees' abilities and skills. Employees' satisfaction with their manager attitude is not less important than previous factors. Therefore, hotel managers should pay attention to create satisfied employees through different techniques in order to generate effective and efficient employees at their hotels. Giving power to the employees at the four-star hotel (EM) found to have the greatest effect on employee performance. As such it highly recommended empowering the subordinates to get the desired results like high EP specifically inside the hotel sector where giving information about facts and authority to the subordinate enhances the employee and hotel effectiveness.

Due to the small sample size, this study failed to generalize the findings to the whole hotel industry in Jordan. Besides, the current study is limited to the four-star hotels' sector in Jordan that are located in the capital Amman and not all four stars hotels in Jordan. Besides that, there are few limitations of the study that worth to be addressed. With the increase in the number of respondents, more advanced statistical analyses can be carried out to confirm the proposed research model. Furthermore, it is interesting to compare the findings between four-star hotels in different states as different environmental factors may have influences on EP too. In addition, it is also interesting to compare the findings between four-star hotels and other categorized hotels such as five or three stars hotels in Jordan. This study did not consider detailed characteristics of hotels as different types of the hotel (such as international chain, independently owned, local chain) might have a significant influence on EP too. Hence, considering this gap by comparing the findings in different types of hotels may an interesting insight for future studies. Finally, yet importantly, this study focused only on the hotel-related factors and failed into taking consideration of other related factors such as employee-related factors and job-related factors. By taken into consideration all aforementioned variables may provide a more holistic picture of the study of EP, which is worth to be considered in future studies. As for the period of the study, it is noteworthy that the study was conducted in 2019.

\section{References}

Ağar, C. C. (2012). The Relationship between Organizational Structure and Job Involvement in Labour and Technology-Intensive Industrial Enterprises: A Comparative Analysis Based on a Field Study. International Journal of Business and Commerce, 2(2), 2-20.

Alfandi, A. (2016a). Selected Antecedents Impacts on Employees performance. Paper presented at the 2016 
Prague International Academic Conference. September 4-7, 2016. Prague, Czech Republic.

Alfandi, A. (2016b).Training Impact on the Performance of Employees "a case of Jordanian travel and tourism institutions. International Business Management, 10(4), 377-384. http://docsdrive.com/pdfs/medwelljournals/ibm/2016/377-384.pdf

Alfandi, A. (2020). Manager Attitude Impact on the Performance of Employees "A Case of Jordanian Travel and Tourism Institutions". International Business Research, 13(1). https://doi.org/10.5539/ibr.v13n1p136

Alsheikh, G. A., Abd-Halim, M. S., Alremawi, M. S., \& Tambi, A. M. (2018). The Mediating Role of Organization Culture on the Relationship between Eemployee Performance and Antecedents in the Hotel Sector. Journal of Reviews on Global Economics, 6(1), 489-497. https://doi.org/10.6000/1929-7092.2017.06.49

Al-Yahya, K. O. (2008). Power-Influence in Decision Making, Competence Utilization, and Oganaization Culture in Public Organizations: The Arab World in Comparative Perspective. Journal of Public Administration Research and Theory, 19(1), 385-407. https://doi.org/10.1093/jopart/mun005

Armstrong, M. (2000). Understanding training. Human Resource Management Practice, Kogan page limited, London, pp543.

Assaf, A. G., \& Josiassen, A. (2016). Frontier analysis: A state-of the-art review and meta-analysis. Journal of travel research, 55(5), 612-627. https://doi.org/10.1177/0047287515569776.

Badado, I. (2006). Human resources evaluation in the Jordanian Tourism sector. Conference of tourism economies: reality and hope. Al-Hashemite University, October, Zarqa, Jordan.

Bakker, A., \& Schaufeli, W. B. (2008). Positive organizational behavior: Engaged employees in flourishing organizations. Journal of Organizational Behaviour, 29(1), 147-154. https://doi.org/10.1002/job.515

Baum, T., \& Devine, F. (2007). Skills and training in the hotel sector: The Case of front office employment in Northern Ireland. Tourism and Hospitality Research, 7(3), 269-280. https://doi.org/10.5465/amr.1984.4277657

Boxall, P., \& Purcell, J. (2011). Strategy and Human Resource Management, Palgrave Macmillan, Basingstoke.

Choong, Y., Wong, K., \& Lau, T. (2011). Intrinsic Motivation and Organizational Commitment in the Malaysian Private Higher Education Institutions: An Empirical Study. Journal of Arts, Science \& Commerce, 2(4).

Cole, G. A. (2002). Personnel and Human Resource Management (5th ed.).York Publishers, Continuum London, UK.

Conner, D. S., \& Douglas, S. C. (2005). Organizationally-induced work stress, The Role of Employee Bureaucratic Orientation. Personnel Review, 34(2), 201-224. https://doi.org/10.1108/00483480510579439

Cooke, F. L. (2000). Human Resource Strategy to improve Organizational Performance: A route for British firms. Working Paper No. 9 EWERC, Manchester School of Management.

Daft, R. L., \& Weick, K. E. (1984). Toward a model of organizations as interpretation systems. Academy of Management Review, 9(2), 284-295. https://doi.org/10.1108/14634449910303603

Duvall, C. K. (1999). Developing individual freedom to act: EM in the knowledge organization. Participation and Empowerment. An International Journal, 7(8), 204-212.

Edgar, F., \& Geare, A. (2005). HRM practice and employee attitudes: different measures - different results. Personnel Review, 34(5), 534-549. https://doi.org/10.1108/00483480510612503

Egan, T. M., Yang, B., \& Bartlett, K. R. (2004). The Effects of Organizational Learning Culture and Job Satisfaction on Motivation to Transfer Learning and Turnover Intention, Human Resource Development Quarterly, 15(3), 279-301. https://doi.org/10.1002/hrdq.1104

Elnaga, A., \& Imran, A. (2013). The Effect of Training on employee performance. European Journal of Business and Management, 5(4).

Elnihewi, I. M. (2015). The Relationship between Contingency and Institutional Factors, and Organisational Performance through the Performance Measures of Libyan Commercial Banks (Doctor of Philosophy). UUM, Malaysia.

Ferris, G. R., Arthur, M. M., Berkson, H. M., Kaplan, D. M., Harrell-Cook, G., \& Frink, D. D. (1998). Toward a social context theory of the human resource management-organization effectiveness relationship. Human 
Resource Management Review, 8(3), 235-264. https://doi.org/10.1016/S1053-4822(98)90004-3

Furnham, A., \& Gunter, B. (1993). Corporate Assessment: Auditing \& Company Personality. Rout ledge. London.

Galanou, E., \& Priporas, C. V. (2009). A model for evaluating the effectiveness of middle managers training courses: evidence from a major banking organization in Greece. International Journal of Training and Development, 13(4), 221-245. https://doi.org/10.1111/j.1468-2419.2009.00329.x

Gana, A. B., \& Bababe, F. B. (2011). The Effects of Motivation on Workers Performance (a case study of Maiduguri Flour Mill Ltd. Borno State, Nigeria.). Continental J. Social Sciences, 4(2), 8-11.

Garavan, T. N. (1997). Interpersonal skills training for quality service interactions. Industrial and Commercial Training, 29, 70-77.

Garg, G., \& Krishnan, V. R. (2003). Transformational Leadership and Organizational Structure: The Role of Value-Based Leadership. In S. Bhargava (Ed.), Transformational leadership: Value-based management for Indian organizations, Response Books, Sage Publications.

Gautam, P. K. (2018). Training Culture and Employees Performance in Nepali Banking Industry. The International Research Journal of Management Sceince, 3(1). Retrieved from https://ncm.edu.np/wp-content/uploads/2018/12/Training-culture.pdf

Ghani, A. (2006). The Influence of Leadership Style, organization structre and Work Motivation to employee performance of Processed Wood Industry in Makasar City. Brawijaya University, Malang. South Sulawesi.

Glaser, S., Zamanou, S., \& Hacker, K. (1987). Measuring and interpreting organizational culture. Management Communication Quarterly, 1, 173-198. https://doi.org/10.1177/0893318987001002003

Griffin, M. A., \& Neal, A. (2000). Perceptions of Safety at Work: A Framework for Linking Safety Climate to Safety Performance, Knowledge, and Motivation. Journal of Occupational Health Psychology, 5(3), 347-358. https://doi.org/10.1037/1076-8998.5.3.347

Hackman, R. J., \& Oldham, G. R. (1975). Development of the Job Diagnostic Survey. Journal of Applied Psychology, 60(2), 159-170. https://doi.org/10.1037/h0076546

Hair, J. F., Money, A. H., Samouel, P., \& Page, M. (2007). Research Methods for Business. John Wiley \& SoNn.

Heck, R. H., \& Marcoulides, G. A. (1993). Organizational Culture and Performance: Proposing and Testing a Model. Organization Science, 4(2), 209-225. https://doi.org/10.1287/orsc.4.2.209

Hellriegel, D., \& Slocum, J. M. (2009). Organizational Behavior. South- Western, U.S.A.

Hofstede, G. (1998). Attitudes, values and organizational culture: Disentangling the concepts. Organization Studies, 19(3), 477-493. https://doi.org/10.1177/017084069801900305

Horng, J. S., \& Lin, L. (2013). Training needs assessment in a hotel using 360 degree feedback to develop competency-based MA. Journal of Hospitality and Tourism Management, 20. https://doi.org/10.1016/j.jhtm.2013.06.003

Jabeen, M. (2011). Impact of Performance Appraisal on Employees Motivation. European Journal of Business and Managemen, 3(4). Retrieved from https://iiste.org/Journals/index.php/EJBM/index

Jiang, F. (2011). Effects of Organizational Structre and Culture on employee Communication Behaviors in Chinese Organizations (Master Thesis). University of Houston.

Jordanian Ministry of Tourism and Antiquities. (2019). http://www.mota.gov.jo/Contents/statistics_2018Ar.aspx

Kalkavan, S., \& Katrinli, A. (2014). The Effects of Managerial Coaching Behaviors on the Employees' Perception of Job Satisfaction, Organizational Commitment, and Job Performance: Case Study on Insurance Industry in Turkey. Paper presented at the 10th International Strategic Management Conference 2014. https://doi.org/10.1016/j.sbspro.2014.09.129

Kalleberg, A. L. (1977). Work values and job rewards: A theory of job satisfaction. American sociological review, 42(1), 124-143. https://doi.org/10.2307/2117735

Kaynak, H. (2003). The relationship between total quality management practices and their effects on firm performance. Journal of Operations Management, 21(4), 405-435. https://doi.org/10.1016/S0272-6963(03)00004-4

Kenneth J. H., Wheeler, A. R., \& Kacmar, M. (2009). Leader-Member Exchange and Empowerment: Direct and 
Interactive Effects on Job Satisfaction, Turnover Intentions, and Performance. The Leadership Quarterly, 20, 371-382. https://doi.org/10.1016/j.leaqua.2009.03.006

Khan, I., Dongping, H., \& Ghauri, T. A. (2014). Impact of Attitude on Employees Performance: A Study of Textile Industry in Punjab, Pakistan. World Applied Sciences Journal, 30(1), 191-197. Retrieved from https://www.idosi.org/wasj/wasj30(icmrp)14/25.pdf

Khasawneh, M. S., \& Alfandi, A. M. (2019). Determining Behaviour Intentions from the Overall Destination Image and Risk Perception. Tourism and Hospitality Management, 25(2), 355-375. https://doi.org/10.20867/thm.25.2.6

Klein, H. J., \& Kim, S. J. (1998). A Field Study of the Influence of Situational Constraints, Leader-Member Exchange, and Goal Commitment on Performance, the Academy of Management Journal, 41(1), 88-95. https://doi.org/10.5465/256900

Liao, C., Chuang, S. H., \& To, P. L. (2011). How Knowledge Management Mediates The Relationship Between Environment and Organizational Structure. Journal of Business Research, 64, 728-736. https://doi.org/10.1016/j.jbusres.2010.08.001

Liden, C. R., \& Graen, G. (1980). Generalizability of the Vertical Dyad Linkage Model of Leadership, The Academy of Management Journal, 23(3), 451-465. https://doi.org/10.2307/255511

Liden, C. R., \& John M. M. (1998). Multidimensionality of Leader-Member Exchange: An Empirical Assessment through Scale Development, Journal of Management, 24(1), 43-72. https://doi.org/10.1016/S0149-2063(99)80053-1

Mathis, R. L., \& Jackson, J. H. (2009). Human Resource Management. Mason, OH, USA: South-Western Cengage Learning, pp324.

McNeese-Smith, D. K. (1997). The Influence of Manager Behavior on Nurses' Job Satisfaction, Productivity, and Commitment. JONA The Journal of Nursing Administration, 27(9), 47-77. https://doi.org/10.1097/00005110-199709000-00011

Mehrabi, J., Alemzadeh, M., \& Jadidi, M. (2013). Explaining the Relationship between Organizational Structre and Dimensions of Learning Organizations (Case study: Education Organization in Boroojerd County and the Related Departments). International Journal of Academic Research in Business and Social Sciences, 3(4), 116-128.

Pellegrini, E. K., \& Scandura, T. A. (2006). Leader-Member Exchange (LMX), Paternalism, and Delegation in The Turkish Business Culture: An Empirical Investigation. Journal of International Business Studies, 37(1), 264-279. https://doi.org/10.1057/palgrave.jibs.8400185

Polo, F., Cervai, S., \& Kantola, J. (2018). Training culture: a new conceptualization to capture values and meanings of training in organizations. Journal of Workplace Learning, 30(3), 162-173. https://doi.org/10.1108/JWL-01-2018-0024

Roscoe, J. T. (1975). Fundamental research statistic for behavioral sciences (2 ed.): New York: Holt Reinhart \& Winston.

Rothwell, W. J., \& Hohne, C. K. et al. (2007). Human Performance Improvement. Building Practitioner Competence, Gulf Publishing Company.

Rousseau, D. (1991). Quantitative assessment of organizational culture. Group and Organizations Studies, 15(4), 448-460.

Scandura T. A., \& Schriesheim, C. A. (1994). Leader- Member Exchange and Supervisor Career Mentoring As Complementary Constructs in Leadership Research, Academy of Management Journal, 37(6), 1588-1602. https://doi.org/10.2307/256800

Schein, E. H. (2011). Leadership and organizational culture. New York, NY: Wiley.

Seamen, P., \& Eves, A. (2005). The management of food safety-the role of food hygiene training in the UK service sector. International journal of hospitality management, 25(2), 278-296. https://doi.org/10.1016/j.ijhm.2005.04.004

Somayyeh, S., \& Morteza, P. (2015). Investigation the Role of Knowledge Management in Staff EM (Case Study: General Department of Education, Western Azerbaijan Province). International Journal of Review in Life Sciences, 5(4), 163-168. 
Syauta, J. H., Troena, E. A., Setiawan, M., \& Solimun. (2012). The Influence of Organizational Culture, Organizational Commitment to Job Satisfaction and Employee Performance (Study at Municipal Waterworks of Jayapura, Papua Indonesia). International Journal of Business and Management Invention, $l(1)$.

Tajeddini, K. (2011). Customer Orientation, Learning Orientation, and New Service Development: An Empirical Investigation of the Swiss Hotel Industry. Journal of Hospitality \& Tourism Research, 35(4), 437-468. https://doi.org/10.1177/1096348010380599

Thomas, K. B., \& Velthouse, B. A. (1990). Cognition elements of empowerment: an "interpretive" model of intrinsic task motivation. Academy of Management Review, 15, 666-681.

Tran, Q., \& Tian, Y. (2013). Organizational Structure: Influencing Factors and Impact on a Firm, American Journal of Industrial and Business Management, 3, 229-236. https://doi.org/10.4236/ajibm.2013.32028

Truckenbrodt, Y. B. (2000). The Relationship between Leader-Member Exchange and Commitment and Organizational Citizenship Behavior. Acquisition Review Quarterly, Summer, 233-244.

Uddin, M. J., Luva, R., \& Hossain, S. (2013). Impact of Organizational Culture on Employee Performance and Productivity: A Case Study of Telecommunication Sector in Bangladesh. International Journal of Business and Management, 8(2). https://doi.org/10.5539/ijbm.v8n2p63

Veal, A. J. (2006). Research methods for leisure and tourism: A practical guide (3rd ed.). Financial Times Prentice Hall /Pearson Education, Harlow, England.

Wunderlich, N., \& Beck, R. (2017). Time for Climate Change: Leadership, IT Climate, and their Impact on Organizational Performance. Paper presented at the Proceedings of the 50th Hawaii International Conference on System Sciences. https://doi.org/10.24251/HICSS.2017.611

Zhang, C., Meiqing, L. M., \& Xu, S. (2019). Can a Leader's Positive Evaluation Improve Occupational Satisfaction of Employees? Based on the Empirical Investigation of a Real Estate Enterprise G Province Branch. International Business Research, 12(11). https://doi.org/10.5539/ibr.v12n11p57

\section{Copyrights}

Copyright for this article is retained by the author(s), with first publication rights granted to the journal.

This is an open-access article distributed under the terms and conditions of the Creative Commons Attribution license (http://creativecommons.org/licenses/by/4.0/). 